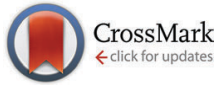

Cite this: J. Mater. Chem. C, 2015, 3, 8916

\title{
Influence of fluorination in $\pi$-extended backbone polydiketopyrrolopyrroles on charge carrier mobility and depth-dependent molecular alignment $\uparrow$
}

\author{
C. J. Mueller, ${ }^{a}$ E. Gann, ${ }^{\text {bc }}$ C. R. McNeill ${ }^{c}$ and M. Thelakkat*a
}

A series of $\pi$-extended polydiketopyrrolo[3,4-c]pyrroles with a varying degree of fluorination on the thiophene-phenyl-thiophene comonomer was synthesized by Stille polycondensation. The influence of the degree of fluorination was studied with regard to the polymer properties, such as absorption, electrochemical redox potentials, the solid state structure as well as depth-dependent molecular alignment in thin films. Additionally, their performance in organic field effect transistors was evaluated. Whereas fluorination slightly increases the alkyl lamella and shrinks the $\pi-\pi$ spacings, the coherence lengths were found to improve significantly in both directions. All polymers were found to be $p$-type materials when employed in organic field effect transistors (OFET). These devices can be tuned towards ambipolarity in the case of the tetrafluorinated copolymer upon thermal annealing.

Received 30th June 2015 Accepted 31st July 2015

DOI: $10.1039 / c 5 t c 01948 f$

www.rsc.org/MaterialsC of semiconducting polymers the exploitation of diffusive nonbonding heteroatom interactions has been employed. ${ }^{11}$ Two of those interactions are the hydrogen-fluorine and the hydrogenoxygen interactions that help lock the conformation of the polymer backbone into a more planarized state. In low bandgap polymers, the influence of fluorination on regioselectivity of the resulting copolymer structure has also been reported. ${ }^{12}$ Not only fluorinated phenylene units have been shown to be valuable building blocks for semiconducting copolymers, ${ }^{13}$ but recently it has been shown that for the TPT motif, bifluorination or bialkoxylation of the central phenyl unit facilitates charge transport and leads to either preferred edge-on alignment in the case of fluorination or face-on alignment in the case of alkoxylation. ${ }^{9}$ On the other hand, a tetrafluorinated TPT derivative has been employed in oligomers ${ }^{14,15}$ as well as in DPP copolymers carrying furanyl flanking units by Sonar et al. ${ }^{16}$ and has been found to provide ambipolarity in OFET devices. It is hitherto unknown whether this ambipolarity is caused by the furanyl-flanking units or the tetrafluorination of the TPT. Therefore it is interesting, to study the effect of fluorination in the conventional DPP copolymers with thienyl flanking units. The impact of tetrafluorination in a TPT moiety on the rotational barrier has been studied by computational methods. ${ }^{17}$

In this contribution we report the synthesis of a series of three extended $\pi$-conjugated PDPPs by using a non-alkylated thiophene- $n$-fluorophenylene-thiophene $(n=0,2,4)$ unit as the comonomer. The crystalline depth-dependant alignment in thin films and the charge transport properties in OFET devices is studied with respect to the degree of fluorination in order to 
gain insight into the structure-property relationship of these $\pi$-extended systems and to evaluate the utility of fluorination in semiconducting polymers as a measure for improving semiconducting material properties. We also evaluate the various non-covalent interactions possible in these derivatives based on experimental crystallographic data of the building blocks.

\section{Results and discussion}

\section{Synthesis}

The synthesis of the stannylated TPT-comonomers is summarized in Fig. 1. For the nonfluorinated TPT unit 4a a synthesis route which has been published for the bis(tributyltin)-analogs ${ }^{18,19}$ was adapted. For the difluorinated compound $\mathbf{4 b}$ as well as the tetrafluorinated $\mathbf{4 c}$, a direct lithiation from $2 \mathbf{b}$ and $2 \mathbf{c}$, respectively, has been reported. ${ }^{16,20}$ We found that monostannylated compounds that are obtained as byproducts from direct lithiation of $\mathbf{2 a - c}$ are difficult to separate even by multiple recrystallizations and sublimations. Therefore we adopted a different synthetic route involving first bromination followed by lithiation and stannylation to obtain $\mathbf{4 b}$ and $\mathbf{4 c}$. The almost quantitative conversion achieved in this bromination route employed here results in high monomer purities. Therefore, this bromination route was employed for all the three stannylated DPP derivatives. In detail, starting from the 1,4-dibrominated phenylene compounds 1a-c a Stille coupling was employed to obtain the TPT blocks 2a-c. Subsequent bromination with NBS in DMF yielded the dibrominated TPT blocks 3a-c in good yields, especially for the fluorinated derivatives where the yield was $80-95 \%$. Lithiation of 3a-c in $\mathrm{THF}$ at $-78{ }^{\circ} \mathrm{C}$ followed by quenching with trimethyltin chloride gave the desired monomers 4a-c. For the fluorinated compounds $\mathbf{4 b}$ and $\mathbf{4 c}$ the stannylation was quantitative. For all three monomers it should be noted that purification is feasible by crystallization due to the high crystallinity of the obtained compounds.

The thienyl-DPP monomer $\mathbf{5}$ was synthesized following a literature procedure, ${ }^{21}$ which was adapted to increase the yield and purity. Polymerizations were carried out in chlorobenzene at $180{ }^{\circ} \mathrm{C}$ under microwave conditions using $\mathrm{Pd}_{2}(\mathrm{dba})_{3}$ with $\mathrm{P}(o \text {-Tol })_{3}$ as the catalytic system. ${ }^{22}$ The resulting polymers are named after their respective DPP aryl flanking units [Ar] and comonomer $M_{\text {co }}$ (see Fig. 2). ${ }^{23}$ All polymers were endcapped with thiophene on both ends. Detailed procedures are given in the Experimental section. All polymers were obtained in high number average molecular weights $\left(M_{\mathrm{n}}\right)$ in the range of 20 400-38100 kg mol ${ }^{-1}$ and dispersities $(\nexists)$ between 1.9 and 2.3 (Table 1). The individual GPC traces are given in the ESI $\dagger$ (Fig. S1-S3, ESI $\dagger$ ) and show a monomodal distribution for every polymer. All polymerizations were carried out using similar conditions regarding concentrations, degree of monomer purities, temperatures and catalytic system. All compounds were polymerized to the precipitation limit in chlorobenzene at $180{ }^{\circ} \mathrm{C}$. The molecular weight of the fluorinated polymers is therefore smaller due to the lower solubility of these polymers upon introduction of fluorine groups.

This behaviour has been reported before and is ascribed to the higher degree of aggregation occurring in fluorinated conjugated polymers. ${ }^{24}$ However, all three polymers are soluble and processable from chloroform. It has been shown earlier by Janssen et al. that the aggregation behaviour in PDPPs plays a significant role in determining alignment in thin film and the morphology of polymer/fullerene blends. Furthermore it was shown that these effects can be influenced by either tuning the solubilizing alkyl sidechains ${ }^{5}$ or the aromatic units along the backbone. ${ }^{6}$

Thermogravimetric analysis (see ESI, $\dagger$ Fig. S6) shows very high decomposition onsets $T_{5 \%}$ around $400{ }^{\circ} \mathrm{C}$ for all three derivatives, as is common for PDPPs.

The melting points of PDPPs are usually very high and close to their respective decomposition onsets which makes them difficult to observe using conventional dynamic scanning calorimetry (DSC). We therefore evaluated the thermal properties of these three polymers using a Flash-DSC setup with heating rates from $50 \mathrm{~K} \mathrm{~s}^{-1}$ to $1000 \mathrm{~K} \mathrm{~s}^{-1}$. The representative $200 \mathrm{~K} \mathrm{~s}^{-1}$ heating and cooling curves are shown in Fig. $4 \mathrm{~b}$ and
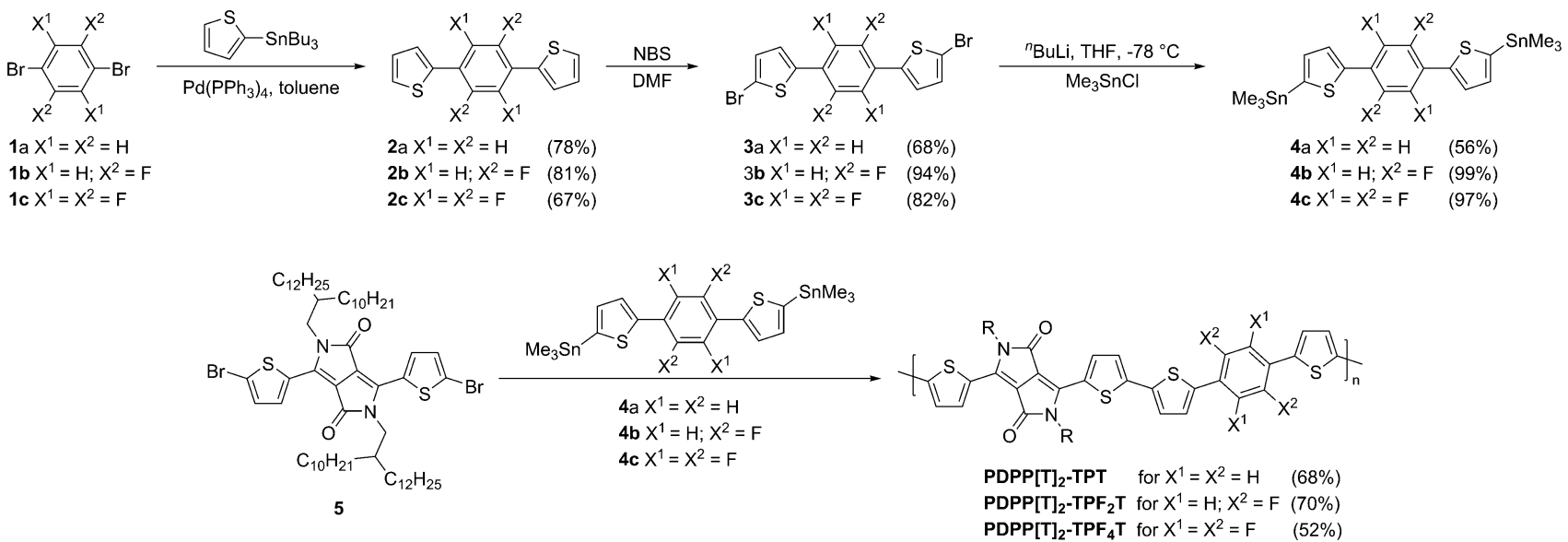

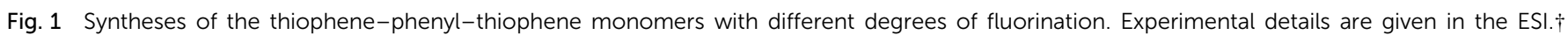
Synthesis of the extended PDPP-TPF $T_{n}$ copolymers by Stille-polycondensation. All yields are given in parentheses. 


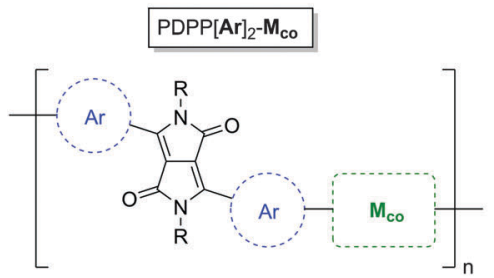

For example: PDPP[T $]_{2}-\mathrm{TPT}: \mathbf{A r}=\mathrm{T}, \mathbf{M}_{\mathrm{co}}=\mathrm{TPT}$
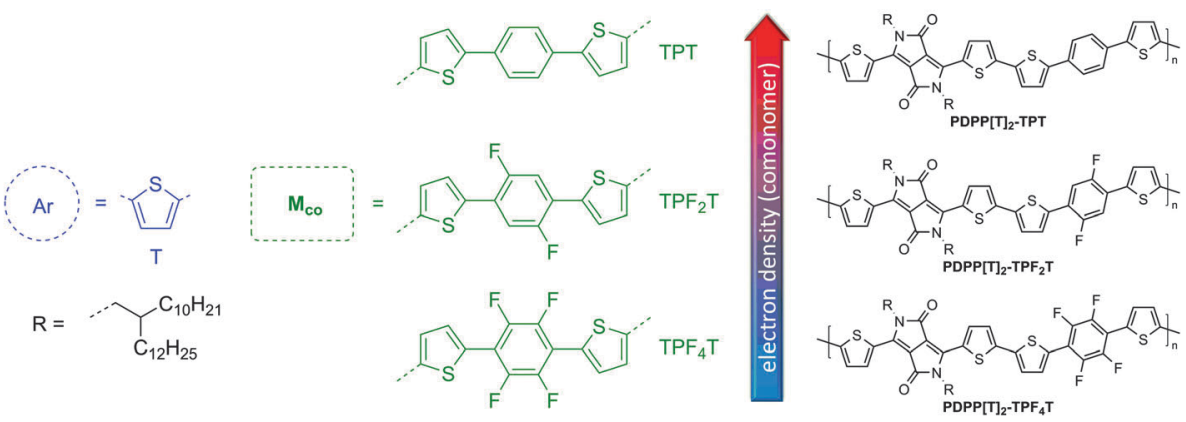

Fig. 2 Structures of the new extended PDPP $[T]_{2}-\mathrm{TPF}_{n} T$ polymers in order of the overall electron density. R $=2$-Decyltetradecyl $(\mathrm{C} 10 / \mathrm{C} 14)$. The systematic nomenclature of the DPP copolymers is adopted from our earlier publication. ${ }^{23}$

Table 1 Intrinsic properties of the synthesized DPP polymers

\begin{tabular}{|c|c|c|c|c|c|c|c|c|c|c|c|}
\hline Polymer & $M_{\mathrm{n}}^{a}\left[\mathrm{~kg} \mathrm{~mol}^{-1}\right]$ & $M_{\mathrm{w}}{ }^{a}\left[\mathrm{~kg} \mathrm{~mol}^{-1}\right]$ & $D^{b}$ & $\mathrm{DP}_{\mathrm{n}}^{c}$ & $T_{5 \%}{ }^{d}\left[{ }^{\circ} \mathrm{C}\right]$ & $T_{\mathrm{m}}{ }^{e}\left[{ }^{\circ} \mathrm{C}\right]$ & $T_{\mathrm{c}}^{e}\left[{ }^{\circ} \mathrm{C}\right]$ & $\operatorname{IP}^{f}[\mathrm{eV}]$ & $\mathrm{EA}^{g}[\mathrm{eV}]$ & $E_{\mathrm{CV}}{ }^{h}[\mathrm{eV}]$ & $E_{\mathrm{opt}}^{i}[\mathrm{eV}]$ \\
\hline $\mathrm{PDPP}[\mathrm{T}]_{2}-\mathrm{TPT}$ & 38.1 & 71.4 & 1.9 & 31 & 389 & 307 & 253 & -5.69 & -3.61 & 2.08 & 1.51 \\
\hline $\operatorname{PDPP}[\mathrm{T}]_{2}-\mathrm{TPF}_{2} \mathrm{~T}$ & 24.5 & 53.1 & 2.2 & 20 & 406 & 337 & 289 & -5.72 & -3.60 & 2.12 & 1.46 \\
\hline $\mathrm{PDPP}[\mathrm{T}]]_{2}-\mathrm{TPF}_{4} \mathrm{~T}$ & 20.4 & 47.2 & 2.3 & 16 & 394 & 344 & 303 & -5.89 & -3.97 & 1.92 & 1.47 \\
\hline
\end{tabular}

${ }^{a}$ Determined by GPC at $150{ }^{\circ} \mathrm{C}$ using $1,2,4$-trichlorobenzene as the eluent. ${ }^{b}$ Dispersity. ${ }^{c}$ Degree of polymerization calculated from $M_{\mathrm{n}}$. ${ }^{d}$ Decomposition onset $(5 \%)$ determined by TGA. ${ }^{e}$ Average Flash-DSC peak melting temperature $\left(T_{\mathrm{m}}\right)$ and crystallization temperature $\left(T_{\mathrm{c}}\right)$ at $-200 \mathrm{~K} \mathrm{~s}^{-1} .{ }^{f}$ Ionisation potential (HOMO). ${ }^{g}$ Electron affinity (LUMO). ${ }^{h}$ Band-gap determined by cyclic voltammetry in thin film. ${ }^{i}$ Optical gap determined from absorption onset in film.

the individual heating and cooling curves for all scan rates are shown in the ESI $\dagger$ (Fig. S4). The respective melting points determined from the average peak value for the different ramping speeds are summarized in Table 1 . The nonfluorinated PDPP $[\mathrm{T}]_{2}-\mathrm{TPT}$ shows the lowest melting temperature $\left(307{ }^{\circ} \mathrm{C}\right)$ whereas fluorination leads to increased melting temperatures of $337{ }^{\circ} \mathrm{C}$ and $344{ }^{\circ} \mathrm{C}$ for the di- and tetrafluorinated copolymers, respectively. This is in accordance with our previous reasoning on differences in molecular weight due to increased aggregation in the fluorinated polymers. Crystallization temperatures are rate-dependant due to the kinetic nature of crystallization. The crystallization temperatures derived from the $-200 \mathrm{~K} \mathrm{~s}^{-1}$ cooling curve given in Table 1 are exemplary and show the same trend as the melting temperatures (Fig. 4b).

The optical properties of the three polymers were investigated by absorption as well as photoluminescence measurements. The individual solution as well as solid-state spectra are shown in Fig. 3.

All three polymers show similar absorption patterns and an almost identical optical gap of $1.5 \mathrm{eV}$ (see Table 1). When comparing the individual solution spectra (Fig. 3a), a slight shift in peak positions for the visible absorption band becomes observable, which is not apparent in the solid state spectra (Fig. 3b). More specifically, when comparing the solution and film absorption spectra of the three individual compounds (Fig. 3c), a notable change in absorption behaviour is observed only by the non-fluorinated PDPP $[\mathrm{T}]_{2}-\mathrm{TPT}$. Upon di-fluorination in PDPP $[\mathrm{T}]_{2}-\mathrm{TPF}_{2} \mathrm{~T}$, the solution and thin film spectra become much more similar. Finally, for the tetrafluorinated $\operatorname{PDPP}[\mathrm{T}]_{2}-$ $\mathrm{TPF}_{4} \mathrm{~T}$ both absorption curves are more or less identical. We ascribe this behaviour to the strong aggregation of the fluorinated polymers and the presence of aggregates in the solutions that don't differ significantly from those finally formed in film. This finding is supported by the fact that the photoluminescence intensity for PDPP $[\mathrm{T}]_{2}-\mathrm{TPT}$ in solution is stronger by a factor of about 3 than those from the fluorinated counterparts $\operatorname{PDPP}[\mathrm{T}]_{2}-\mathrm{TPF}_{2} \mathrm{~T}$ and $\mathrm{PDPP}[\mathrm{T}]_{2}-\mathrm{TPF}_{4} \mathrm{~T}$. This photoluminescence quenching is again ascribed to the strong aggregation of the fluorinated polymers in solutions. In thin film, when all the three polymers show the absorption spectrum of the aggregated species, the photoluminescence intensity is comparable for all three polymers.

Oxidation and reduction potentials of the individual polymers were studied by cyclic voltammetry. The individual cyclic voltammograms are shown in ESI† (Fig. S5). The energy levels of the polymers were calculated from the redox half step potentials calibrated against ferrocene in acetonitrile, for which a work function of $-5.23 \mathrm{eV}$ for the ferrocene/ferrocenium redox couple is taken from literature. ${ }^{25}$ All potentials were obtained using a standard three-electrode cyclic voltammetry setup. Polymers were spincoated onto ITO glass slides which were used as the working electrode and measurements were carried out in solutions containing a $0.1 \mathrm{M}$ tetra- $n$-butylammonium hexafluorophosphate/ acetonitrile electrolyte solution at a scan rate of $100 \mathrm{mV} \mathrm{s}^{-1}$. The values for the ionization potential (IP), which closely resembles the highest occupied molecular orbital (HOMO) as well as the electron affinity (EA), which resembles the lowest unoccupied molecular orbital (LUMO) are summarized in Table 1 and comparatively shown in Fig. $4 .{ }^{26}$ Interestingly, when compared to the nonfluorinated PDPP[T $]_{2}$-TPT (IP: $-5.69 \mathrm{eV}$, EA: $3.61 \mathrm{eV}$ ), difluorination in PDPP $[\mathrm{T}]_{2}-\mathrm{TPF}_{2} \mathrm{~T}$ only has a negligible effect on both, IP $(-5.72 \mathrm{eV})$ and EA $(-3.60 \mathrm{eV})$. The fundamental bandgap $E_{\mathrm{CV}}$ of $2.1 \mathrm{eV}$ is therefore also identical for both polymers. Upon introduction of two more fluorine atoms yielding $\mathrm{PDPP}[\mathrm{T}]_{2}-\mathrm{TPF}_{4} \mathrm{~T}$ a 

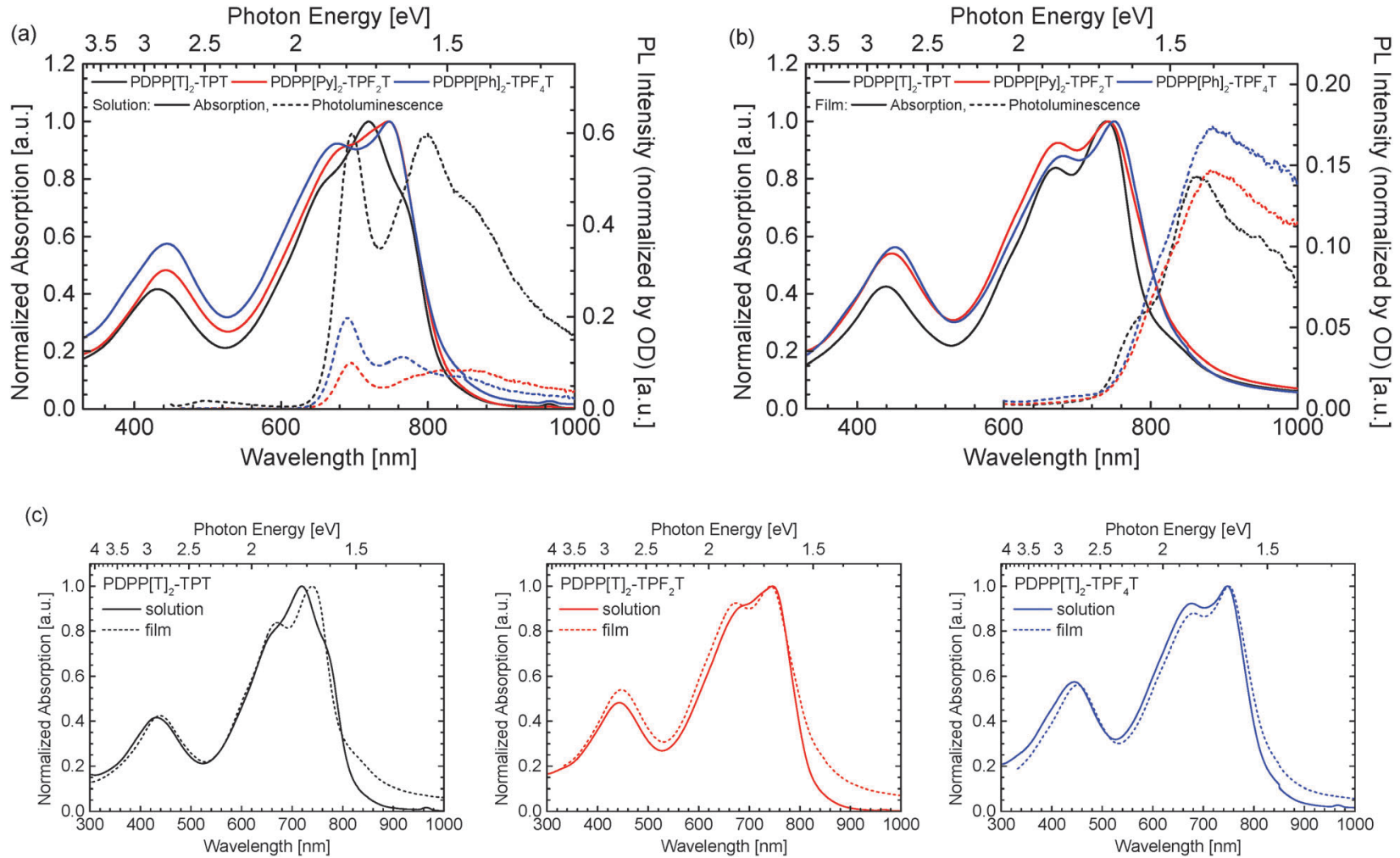

Fig. 3 Absorption and photoluminescence data for the PDPP[T $]_{2}-\mathrm{TPF}_{n} T$ copolymers measured in (a) chloroform solution and in (b) film. A comparison of solution and film absorption spectra is shown in (c).
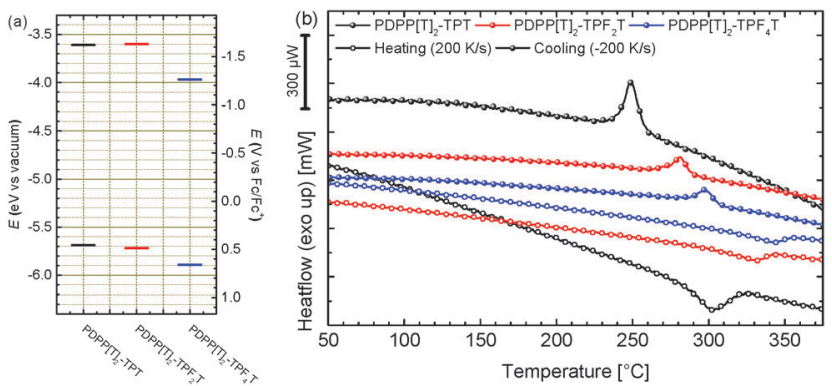

Fig. 4 (a) Energy level comparison for the extended backbone DPP copolymers with a varying degree of fluorination. Values are determined by cyclic voltammetry in thin film; (b) Flash-DSC curves for $200 \mathrm{~K} \mathrm{~s}^{-1}$ heating/cooling rates. See ESI† (Fig. S5) for additional scan rates.

clear shift of both energy levels towards lower values can be observed, resulting in an IP of $-5.89 \mathrm{eV}$ and an EA of $-3.97 \mathrm{eV}$ as well as a fundamental bandgap of $1.92 \mathrm{eV}$. Compared to the optical gap these values are significantly larger, which can be taken as an indicator for large a large exciton binding energy $E_{\mathrm{b}}$ in these polymers. ${ }^{26}$

\section{Influence of fluorination on backbone planarization: weak non-covalent interactions}

There are several contradictory reports in the recent literature on the origin and the exact conformation that are caused by heteroatom interactions. Whereas elaborate theoretical work by Ratner et al. based on quantum chemical calculations mainly favours hydrogen-heteroatom interactions such as $\mathrm{H} \cdots \mathrm{F}$, $\mathrm{H} \cdots \mathrm{O}, \mathrm{H} \cdots \mathrm{S}$ etc., several reports claim that $\mathrm{S} \cdots \mathrm{F}$ and $\mathrm{O} \cdots \mathrm{F}$ interactions influence the planarization of semiconducting polymer backbones. ${ }^{9,27}$ It has also been reported, that the interaction between heteroatoms such as $\mathrm{S} \cdots \mathrm{F}$ and $\mathrm{O} \cdots \mathrm{F}$ are nearly zero. ${ }^{11}$

We like to emphasize, that for most of the motifs employed in these polymers, experimental structural data for building blocks is available from single crystal crystallography. We therefore analysed the Cambridge Crystallographic Database Centre (CCDC) library for the various low molecular weight TPT motifs with different degrees of fluorination on the central phenyl moiety. The experimental data supports the model that has been theoretically established by Ratner et al., i.e. for the difluorinated $\mathrm{TPF}_{2} \mathrm{~T}$ unit the fluorine atoms on the phenyl ring point towards the hydrogen atoms of the adjacent thiophene units. ${ }^{14}$ This experimental evidence does not support the proposed $\mathrm{S} \cdots \mathrm{F}$ interactions in $\mathrm{TPF}_{2} \mathrm{~T}$, as reported in literature. ${ }^{9}$

\section{GIWAXS}

Crystalline packing within the polymer thin films was investigated with Grazing Incidence Wide Angle X-ray Scattering (GIWAXS), see Fig. 5. Exposures were taken at incident angles between 0.05 and 0.4 degrees at a resolution of 0.01 degrees near the critical angle $\sim 0.17$ degrees, to capture the highest intensity critical angle scattering, as well as some depth sensitive information (as shown in Fig. 6). 


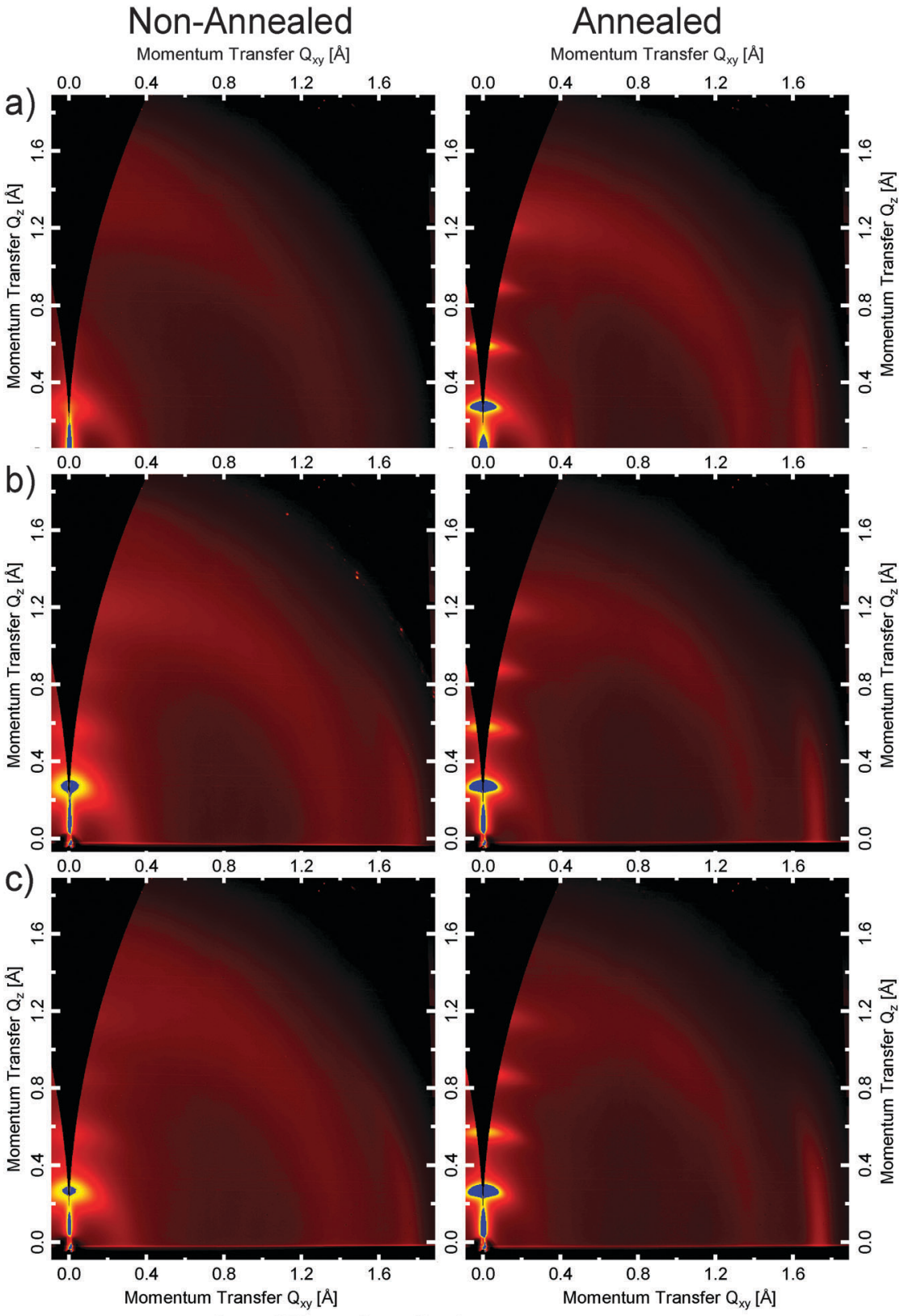

d)

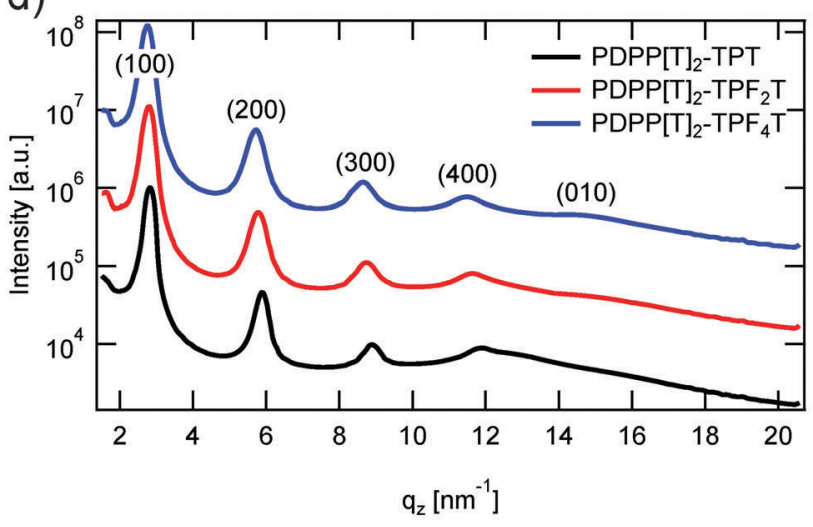

e)

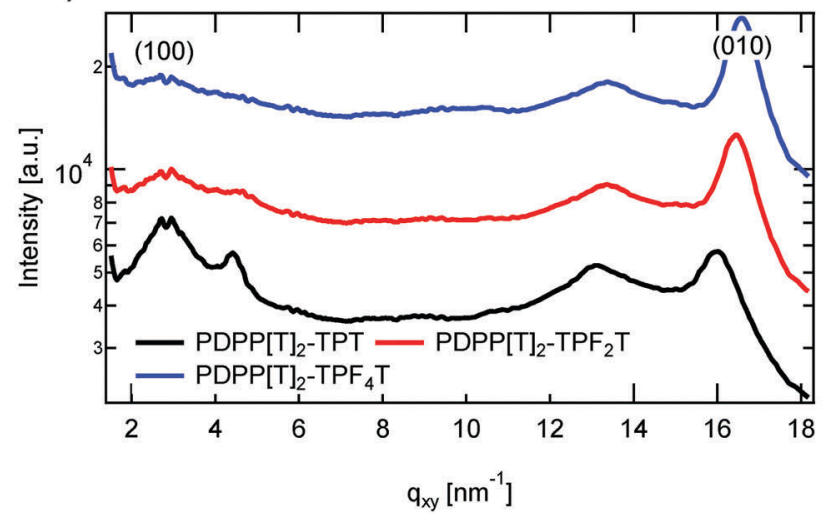

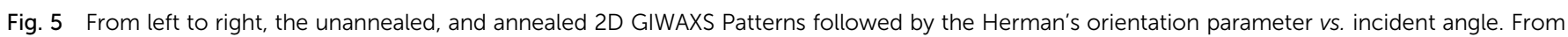

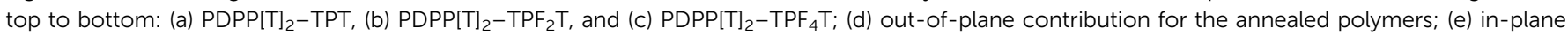
contribution for the annealed polymers. 


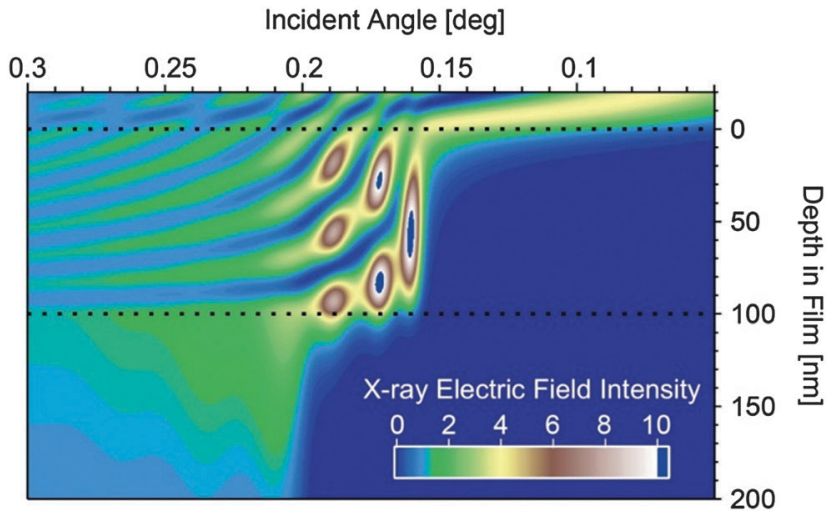

Fig. 6 The calculated X-ray electric field intensity for a $100 \mathrm{~nm}$ thick film on Si. The area between the dotted black lines represents the polymer film. The critical angle at approximately $0.16-0.17$ degrees is seen by the sudden large enhancement of electric field intensity within the polymer film. The critical angle of the lower Si substrate can be seen at $\sim 0.2$ degrees, at which point the $\mathrm{X}$-ray electric field intensity becomes much more uniform throughout the film and substrate. At angles below the critical angle, the electric field intensity within the film is entirely at the surface, within the top $\sim 10 \mathrm{~nm}$.

All scattering patterns show clear alkyl lamella stacking, that is backbone to backbone across the alkyl side chains, and $\pi-\pi$ stacking, from one molecular face to the next. All polymers exhibit liquid crystalline, semi-crystalline diffraction pattern, with little to no mixed index peaks (peaks away from purely out-of-plane or in-plane), indicating that the elements are largely stacking one dimensionally along different directions, and not forming three dimensional crystals. Additionally, all the polymers exhibit a generally edge-on orientation, with alkyl stacking largely out-of-plane and $\pi-\pi$ stacking in-plane.

We can see that the effect of annealing in all cases is the intensification and sharpening of the peaks, with several orders of alkyl lamella stacking apparent, indicating increased crystallinity and larger crystalline domains present within the annealed films. The degree of orientational alignment is quantified by the Herman's orientation paramete ${ }^{28}$ which runs from -0.5 (face-on orientation) to 1 (edge on orientation), of the first order alkyl stacking peak, plotted in the right most column of Fig. 5(a-c). We can see at once that the unannealed films are less well oriented, however all films still have an average edge-on structure. Upon annealing, the orientation is strengthened in all cases towards almost perfect edge on orientation.

To understand the angular dependence of the Hermans parameter vs. angle, the electric field intensity of the X-ray beam is calculated $v s$. angle and depth within a $100 \mathrm{~nm}$ thick polymer film as shown in Fig. 6. Depths greater than $100 \mathrm{~nm}$ represent the silicon substrate, while depths less than 0 represent the ambient environment. Scattering from any depth within the film is proportional to the X-ray electric field intensity at that depth. Thus, at incident angles less than the critical angle $(\sim 0.16$ degrees in the simulation $) \mathrm{X}$-rays scatter exclusively from the upper $\sim 10 \mathrm{~nm}$ of the surface of the polymer film, while between the critical angle of the polymer film and the critical angle of the silicon substrate $(\sim 0.2$ degrees $)$
Table 2 Crystalline parameters found from the GIWAXS patterns. Uncertainties of the final digit are indicated in parentheses after the value

\begin{tabular}{llllll}
\hline Polymer & $T^{a}$ & $\begin{array}{l}d_{\text {alkyl }}{ }^{a} \\
{[\mathrm{~nm}]}\end{array}$ & $\begin{array}{l}\zeta_{\text {alkyl }} c, f \\
{[\mathrm{~nm}]}\end{array}$ & $\begin{array}{l}d_{\pi-\pi}{ }^{d} \\
{[\mathrm{~nm}]}\end{array}$ & $\begin{array}{l}\zeta_{\pi-\pi} e, f \\
{[\mathrm{~nm}]}\end{array}$ \\
\hline $\mathrm{PDPP}[\mathrm{T}]_{2}-\mathrm{TPT}$ & As cast & $2.3(1)$ & $5.1(1)$ & $0.395(3)$ & $2.6(5)$ \\
$\mathrm{PDPP}[\mathrm{T}]]_{2}-\mathrm{TPT}$ & $250{ }^{\circ} \mathrm{C}$ & $2.15(5)$ & $22.3(1)$ & $0.392(1)$ & $5.2(1)$ \\
$\mathrm{PDPP}[\mathrm{T}]_{2}-\mathrm{TPF}_{2} \mathrm{~T}$ & As cast & $2.2(1)$ & $8.25(5)$ & $0.375(1)$ & $5.4(1)$ \\
$\mathrm{PDPP}[\mathrm{T}]_{2}-\mathrm{TPF}_{2} \mathrm{~T}$ & $250{ }^{\circ} \mathrm{C}$ & $2.2(1)$ & $19.3(1)$ & $0.381(1)$ & $7.6(1)$ \\
$\mathrm{PDPP}[\mathrm{T}]_{2}-\mathrm{TPF}_{4} \mathrm{~T}$ & As cast & $2.22(5)$ & $7.82(3)$ & $0.377(1)$ & $5.3(1)$ \\
$\mathrm{PDPP}[\mathrm{T}]_{2}-\mathrm{TPF}_{4} \mathrm{~T}$ & $250{ }^{\circ} \mathrm{C}$ & $2.2(1)$ & $18.9(1)$ & $0.378(1)$ & $8.1(1)$
\end{tabular}

${ }^{a}$ Annealing process. ${ }^{b}$ Alkyl spacing. ${ }^{c}$ Alkyl stacking coherence length. ${ }^{d} \pi-\pi$ stacking spacing. ${ }^{e} \pi-\pi$ stacking coherence length. ${ }^{f}$ The crystal coherence length $\zeta$ gives information about the distance over which order is maintained and is defined as $\zeta=2 \pi / \mathrm{FWHM}$, where FWHM is the full width at half maximum of the first order lamellar stacking or $\pi-\pi$ stacking peak, respectively. It is related to the Scherrer equation, which connects the width of a peak to the crystal size.

the location and intensity of scattering originates from deeper within the film. Finally, above the critical angle of the substrate, the electric field intensity becomes much more even throughout the entire system, averaging out to an intensity of 1 at very high angles. Thus looking at the angular dependence of the Herman's orientation parameter in Fig. 5, we can conclude that for all of the unannealed films, as well as for the annealed PDPP $[\mathrm{T}]_{2}-\mathrm{TPT}$ and $\mathrm{PDPP}[\mathrm{T}]_{2}-\mathrm{TPF}_{2} \mathrm{~T}$ films, the surface region of the samples are less well oriented than the bulk of the film. For PDPP $[\mathrm{T}]_{2}-\mathrm{TPF}_{4} \mathrm{~T}$, on the other hand, the exceptionally high degree of edge-on alignment extends all through the surface upon annealing. Sector averages of the out-of-plane (vertical, $\mathrm{Q}_{z}$ ) and in-plane (horizontal, $\mathrm{Q}_{x y}$ ) directions of the annealed polymer films are shown in Fig. 5d, and the results of fitting the alkyl stacking lamella peaks and $\pi-\pi$ stacking peaks is shown in Table 2 .

We can see that the process of annealing increases the coherence lengths of both types of stacking, but particularly in the alkyl stacking direction, where the coherence length increases by a factor of 4 in the case of PDPP $[\mathrm{T}]_{2}-\mathrm{TPT}$, whereas the increase is only by a bit more than a factor of 2 for both fluorinated polymers. It is clear that the addition of fluorine to the backbone decreases the stacking distance, with the annealed $\operatorname{PDPP}[\mathrm{T}]_{2}-\mathrm{TPF}_{4} \mathrm{~T}$ film having the smallest of the annealed $\pi-\pi$ stacking distances. In the case of the unannealed films, fluorination yields distinctly smaller $\pi-\pi$ stacking values. With the alkyl lamella stacking stretching out at the same time upon fluorination, a general flattening of the unit cell can be deduced.

\section{Charge carrier mobilities}

To investigate the influence of the degree of fluorination on the charge carrier mobilities, the polymers were investigated in organic field effect transistor (OFET) devices using a bottom gate/bottom contact (BGBC) configuration. Details on the device preparation and charge carrier mobility determination are given in the Experimental section.

As typical examples, the $I-V$ transfer as well as output curves for the non-fluorinated PDPP $[\mathrm{T}]_{2}-\mathrm{TPT}$ and the tetrafluorinated $\mathrm{PDPP}[\mathrm{T}]_{2}-\mathrm{TPF}_{4} \mathrm{~T}$ are shown in Fig. 7 and the mobility values are summarized for different annealing conditions in Table 3. 

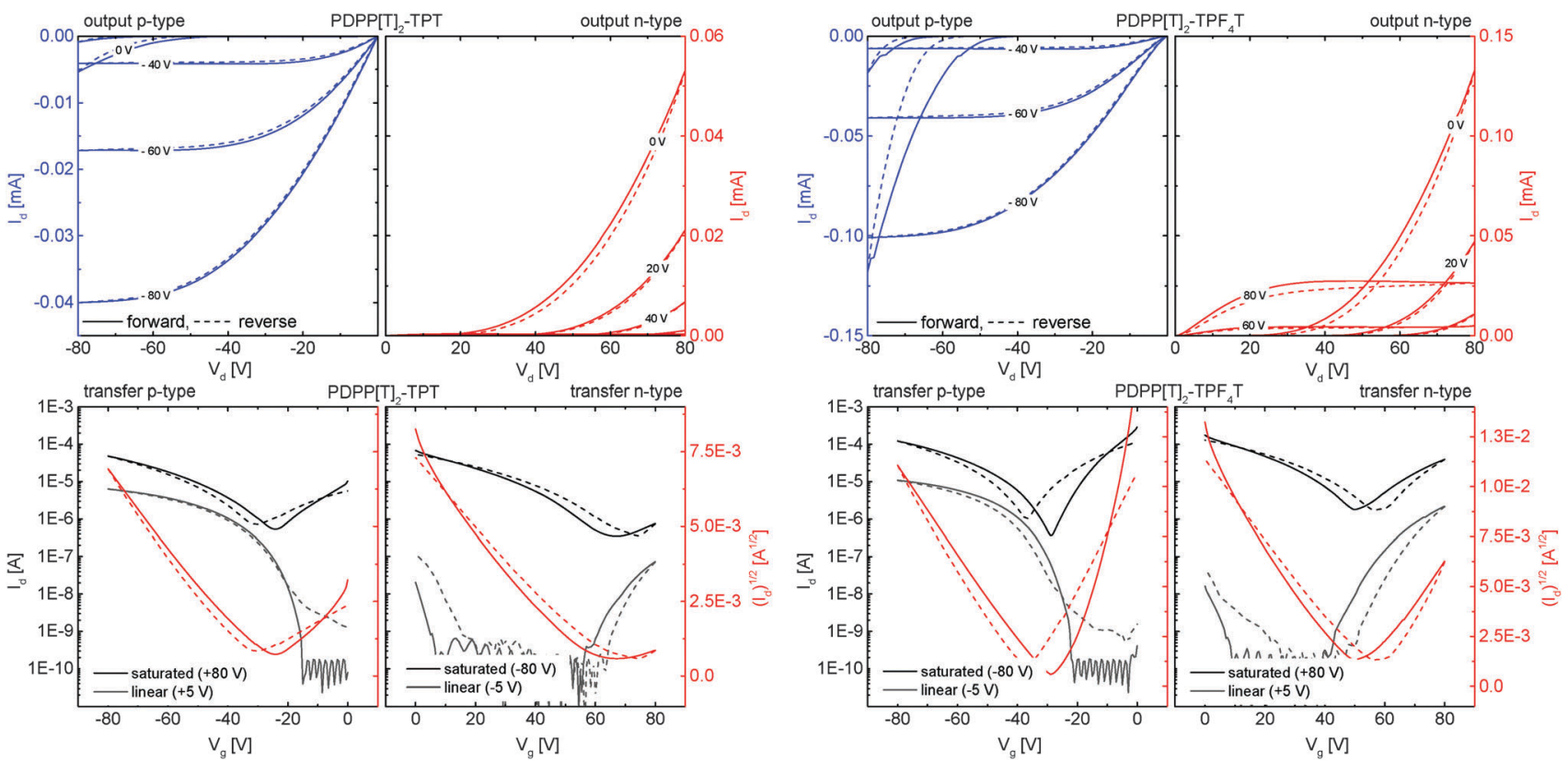

Fig. 7 Representative OFET I-V curves in p-channel (blue output) and $n$-channel (red output) operation for the non-fluorinated PDPP $[T]_{2}-T P T$ (left) and the tetrafluorinated PDPP $[T]_{2}-\mathrm{TPF}_{4} \mathrm{~T}$ (right) after annealing at $350{ }^{\circ} \mathrm{C}$. Solid lines represent forward scans, dashed lines the reverse scans in all graphs. In transfer curves (bottom), the black and gray plots indicate the transfer characteristics in the saturation and linear operation regime, respectively. I- $V$ curves for the difluorinated PDPPIT] $]_{2}-\mathrm{TPF}_{2} \mathrm{~T}$ as well as a scaled comparison of the n-output characteristics for all three polymers are given in the ESI $\dagger$ (Fig. S9 and S10).

Table 3 Average OFET-mobilities of PDPP $\left[\mathrm{Ar}_{2}-\mathrm{TPF}_{n} \mathrm{~T}\right.$ copolymers in a bottom gate/bottom contact configuration in as cast and annealed films

\begin{tabular}{|c|c|c|c|c|c|c|}
\hline & & \multirow{2}{*}{$\begin{array}{l}\text { Annealed }{ }^{b} 200{ }^{\circ} \mathrm{C} \\
\mu_{\mathrm{h}}{ }^{a}\left[\mathrm{~cm}^{2} \mathrm{~V}^{-1} \mathrm{~s}^{-1}\right]\end{array}$} & \multirow{2}{*}{$\begin{array}{l}\text { Annealed } 250{ }^{\circ} \mathrm{C} \\
\mu_{\mathrm{h}}{ }^{a}\left[\mathrm{~cm}^{2} \mathrm{~V}^{-1} \mathrm{~s}^{-1}\right]\end{array}$} & \multirow{2}{*}{$\begin{array}{l}\text { Annealed } 300{ }^{\circ} \mathrm{C} \\
\mu_{\mathrm{h}}{ }^{a}\left[\mathrm{~cm}^{2} \mathrm{~V}^{-1} \mathrm{~s}^{-1}\right]\end{array}$} & \multicolumn{2}{|c|}{ Annealed $^{b} 350{ }^{\circ} \mathrm{C}$} \\
\hline Polymer & $\mu_{\mathrm{h}}^{a}\left[\mathrm{~cm}^{2} \mathrm{~V}^{-1} \mathrm{~s}^{-1}\right]$ & & & & $\mu_{\mathrm{h}}^{a}\left[\mathrm{~cm}^{2} \mathrm{~V}^{-1} \mathrm{~s}^{-1}\right]$ & $\mu_{\mathrm{e}}^{a}\left[\mathrm{~cm}^{2} \mathrm{~V}^{-1} \mathrm{~s}^{-1}\right]$ \\
\hline $\begin{array}{l}\mathrm{PDPP}[\mathrm{T}]_{2}-\mathrm{TPT} \\
\mathrm{PDPP}[\mathrm{T}]_{2}-\mathrm{TPF}_{2} \mathrm{~T} \\
\mathrm{PDPP}[\mathrm{T}]_{2}-\mathrm{TPF}_{4} \mathrm{~T}\end{array}$ & $\begin{array}{l}(2.3 \pm 0.4) \times 10^{-2} \\
(5.7 \pm 0.9) \times 10^{-3} \\
(2.6 \pm 0.5) \times 10^{-3}\end{array}$ & $\begin{array}{l}(4.1 \pm 1.2) \times 10^{-2} \\
(2.0 \pm 0.4) \times 10^{-2} \\
(1.3 \pm 0.2) \times 10^{-2}\end{array}$ & $\begin{array}{l}(2.6 \pm 0.9) \times 10^{-2} \\
(1.5 \pm 0.5) \times 10^{-2} \\
(1.1 \pm 0.3) \times 10^{-2}\end{array}$ & $\begin{array}{l}(5.8 \pm 0.7) \times 10^{-2} \\
(1.9 \pm 0.8) \times 10^{-2} \\
(1.4 \pm 0.4) \times 10^{-2}\end{array}$ & $\begin{array}{l}(3.7 \pm 3.4) \times 10^{-3} \\
(2.5 \pm 0.9) \times 10^{-2} \\
(1.5 \pm 0.8) \times 10^{-2}\end{array}$ & $\begin{array}{l}(2.0 \pm 0.9) \times 10^{-4} \\
(8.0 \pm 3.4) \times 10^{-3} \\
(1.3 \pm 0.5) \times 10^{-2}\end{array}$ \\
\hline
\end{tabular}

${ }^{a}$ Hole $\left(\mu_{\mathrm{h}}\right)$ /electron $\left(\mu_{\mathrm{e}}\right)$ mobilities determined from saturated operation regime. All values were averaged over a minimum of 10 devices.

${ }^{b}$ Annealing was performed for $15 \mathrm{~min}$ in a nitrogen atmosphere. See ESI (Table S2) for threshold voltages and on/off ratios.

The $I-V$ curves for PDPP $[\mathrm{T}]_{2}-\mathrm{TPF}_{2} \mathrm{~T}$ are given in the ESI $\dagger$ (Fig. S9). A comparison of the output curves for all polymers in n-channel operation can also be found in the ESI $\dagger$ (Fig. S10), giving an overview of the output currents in different scales. For the as cast films as well as for annealed films up to $250{ }^{\circ} \mathrm{C}$, no n-channel behavior was observable. For the p-type devices, the threshold voltage was $0 \mathrm{~V}$ for all devices and the non-fluorinated PDPP $[\mathrm{T}]_{2}-$ TPT shows the highest hole mobility $\left(\mu_{\mathrm{h}}=2.3 \times 10^{-2} \mathrm{~cm}^{2} \mathrm{~V}^{-1} \mathrm{~s}^{-1}\right)$. Difluorination leads to a fivefold decrease in hole mobility whereas tetrafluorination in $\mathrm{PDPP}[\mathrm{T}]_{2}-\mathrm{TPF}_{4} \mathrm{~T}$ results in a decrease of one order of magnitude in hole mobility $(2.6 \times$ $\left.10^{-3} \mathrm{~cm}^{2} \mathrm{~V}^{-1} \mathrm{~s}^{-1}\right)$. This decrease in $\mu_{\mathrm{h}}$ stands in contrast to the alignment of the as cast films which is much higher for the fluorinated derivatives as discussed in the GIWAXS section. Although surface alignment plays a crucial role in OFET devices, it is important to note that high hole mobilities are influenced by the electron-richness of the polymer as well as the quality of the dielectric-semiconductor interface. As already discussed, the $\mathrm{S} \cdots \mathrm{F}$ interaction in general is supposed to help planarization of the polymer backbone ${ }^{11}$ which is also in agreement with the structural data from single crystals of the incorporated oligomers. ${ }^{14,15,29-31}$ In a series of fluorinated DPP copolymers, we have earlier shown that fluorination mainly improves the n-type character of semiconducting polymers or leads to ambipolarity in otherwise exclusively p-type materials. ${ }^{23}$

Annealing leads to an increased hole mobility at the cost of higher threshold voltages around $30 \mathrm{~V}$ for the non-fluorinated PDPP $[\mathrm{T}]_{2}-\mathrm{TPT}$ reaching a maximum of $5.8 \times 10^{-2} \mathrm{~cm}^{2} \mathrm{~V}^{-1} \mathrm{~s}^{-1}$ after annealing at $300{ }^{\circ} \mathrm{C}$. This increase can be explained by the higher degree of edge-on alignment as evidenced by the GIWAXS experiments and an $S$-parameter close to 0.9 after annealing. In the fluorinated polymer films, the hole mobility is increased by one order of magnitude upon annealing at temperatures between $200{ }^{\circ} \mathrm{C}$ and $300{ }^{\circ} \mathrm{C}$ to give values in the range of $1-2 \times 10^{-2} \mathrm{~cm}^{2} \mathrm{~V}^{-1} \mathrm{~s}^{-1}$.

Upon annealing at $350{ }^{\circ} \mathrm{C}$, the non-fluorinated $\operatorname{PDPP}[\mathrm{T}]_{2}-$ TPT shows an onset of a weak n-type character with a rather low electron mobility value of $2.0 \times 10^{-4} \mathrm{~cm}^{2} \mathrm{~V}^{-1} \mathrm{~s}^{-1}$ and a high threshold voltage of $54 \mathrm{~V}$, leading to barely visible output even when operated at a high gate voltage of $80 \mathrm{~V}$. Even though it is a 
weak n-type behaviour, it clearly indicates the onset of ambipolar behaviour. On the other hand, for the fluorinated derivatives, annealing at $350{ }^{\circ} \mathrm{C}$ improves the n-channel performance considerably. Thus, electron mobilities of $8.0 \times 10^{-3} \mathrm{~cm}^{2} \mathrm{~V}^{-1} \mathrm{~s}^{-1}$ for $\mathrm{PDPP}[\mathrm{T}]_{2}-\mathrm{TPF}_{2} \mathrm{~T}$ and $1.3 \times 10^{-2} \mathrm{~cm}^{2} \mathrm{~V}^{-1} \mathrm{~s}^{-1}$ for PDPP $[\mathrm{T}]_{2}-\mathrm{TPF}_{4} \mathrm{~T}$ respectively, could be obtained. The threshold voltage for n-channel operation is also decreased with respect to the non-fluorinated polymer and remains at around $50 \mathrm{~V}$. Additionally, in these polymers, the hole-mobility is not negatively influenced by this high-temperature annealing step and remains in the range of $10^{-2} \mathrm{~cm}^{2} \mathrm{~V}^{-1} \mathrm{~s}^{-1}$. The origin of the high threshold voltages could be related to electron trapping at the dielectric/polymer interface. ${ }^{32}$

\section{Experimental section}

\section{Materials and methods}

All reagents were used without further purification unless otherwise noted. Microwave reactions were conducted in sealed containers using a Biotage Initiator Eight + microwave. All polymer ${ }^{1} \mathrm{H}$ and ${ }^{19} \mathrm{~F}$ NMR spectra were recorded on a Varian INOVA 300 spectrometer at $393 \mathrm{~K}$ in 1,1,2,2-tetrachloroethane (TCE) as solvent. The ${ }^{1} \mathrm{H}$ spectra were referenced internally by using the residual solvent resonances. Deuterated solvents were obtained from Deutero. Gel permeation chromatography (GPC) analysis was carried out on an Agilent (Polymer Laboratories Ltd) PL-GPC 220 high temperature chromatographic unit equipped with DP, RI and LS $\left(15^{\circ}\right.$ and $\left.90^{\circ}\right)$ detectors and three linear mixed bed columns of PLgel $13 \mu \mathrm{m}$ (Olexis) with a linear $M_{\mathrm{w}}$ operating range: 500-15000000 $\mathrm{g} \mathrm{mol}^{-1}$. GPC analysis was performed at $150{ }^{\circ} \mathrm{C}$ using 1,2,4-trichlorobenzene as the mobile phase. The samples were prepared by dissolving the polymer $(0.1 \mathrm{wt} \%)$ in the mobile phase solvent in an external oven and the solutions were run without filtration. The molecular weights of the samples were referenced to linear polystyrene $\left(M_{\mathrm{w}}=162-6000000 \mathrm{~g} \mathrm{~mol}^{-1}\right.$, $K=12.100$ and Alpha $=0.707)$ and were not corrected with $K$ and Alpha values for the measured sample. Cyclic voltammetry was performed under moisture- and oxygen-free conditions using a $0.1 \mathrm{M}$ tetra- $n$-butylammonium hexafluorophosphate in acetonitrile electrolyte solution. A standard three-electrode assembly connected to a potentiostat (model 263A, EG\&G Princeton Applied Research) was used at a scanning rate of $100 \mathrm{mV} \mathrm{s}^{-1}$. The working electrode was a $10 \Omega \square^{-1}$ ITO coated glass substrate. The polymers were spincoated onto the ITO substrates from chloroform at $3 \mathrm{mg} \mathrm{mL}^{-1}$ and $1500 \mathrm{rpm}$ to obtain thicknesses of 10-20 nm. A platinum wire in acetonitrile was used as counter electrode and the quasi-reference electrode consisted of an $\mathrm{Ag}$ wire in an $\mathrm{AgNO}_{3}$ /acetonitrile solution (0.1 M). The measurements were calibrated with an external ferrocence/ferrocenium standard, IP and EA values were calculated considering the solvent effects as per a published procedure ${ }^{33}$ using eqn (1) and (2) where the workfunction of $\mathrm{Fc} / \mathrm{Fc}^{+}$is taken to be $-5.23 \mathrm{eV}$. The reduction half-step potential $E_{1 / 2}^{\mathrm{red}}\left(v s . \mathrm{Fc} / \mathrm{Fc}^{+}\right)$is negative whereas the oxidation half-step potential $E_{1 / 2}^{\mathrm{ox}}\left(v s\right.$. $\left.\mathrm{Fc} / \mathrm{Fc}^{+}\right)$is positive.

$$
\mathrm{EA} \approx-5.23 \mathrm{eV}-E_{1 / 2}^{\mathrm{red}}\left(v s . \mathrm{Fc} / \mathrm{Fc}^{+}\right)
$$

$$
\mathrm{IP} \approx-5.23 \mathrm{eV}-E_{1 / 2}^{\mathrm{ox}}\left(v s . \mathrm{Fc} / \mathrm{Fc}^{+}\right)
$$

Absorption measurements were carried out on a JASCO V-670 spectrophotometer. Photoluminescence measurements were carried out on a JASCO FP-8600 spectrofluorometer, excitation wavelengths were chosen at the maximum of the transition around $430 \mathrm{~nm}$ for all samples. Optical properties in solution were measured in chloroform at a concentration of $0.01 \mathrm{mg} \mathrm{mL}^{-1}$ and a path length of $10 \mathrm{~mm}$, films were spin-coated onto glass slides from a $7 \mathrm{mg} \mathrm{mL} \mathrm{mL}^{-1}$ chloroform solution at $1500 \mathrm{rpm}$. Solutions for spin-coating were prepared by dissolving the polymer in chloroform at the given concentration and stirring at $55{ }^{\circ} \mathrm{C}$ for $8 \mathrm{~h}$. Thermogravimetric analysis was performed on a Netzsch STA 449 F3 Jupiter under $\mathrm{N}_{2}$ atmosphere at a heating rate of $10 \mathrm{~K} \mathrm{~min}^{-1}$. Temperature of decomposition $\left(T_{5 \%}\right)$ was calculated from the $5 \%$ degradation step of the respective curve. Flash-DSC measurements have been performed on a Mettler-Toledo Flash DSC $1 .^{34}$

GIWAXS measurements were conducted at the SAXS/WAXS beamline of the Australian Synchrotron. ${ }^{35}$ Samples were prepared by spincoating a polymer film onto an octyltrichlorosilane $/ \mathrm{SiO}_{2}$

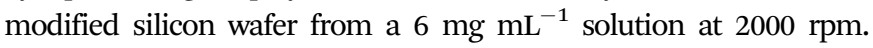
Highly collimated $9 \mathrm{keV}$ X-rays were calibrated to be at a tilt angle of $0 \pm 0.01$ degrees when parallel to the surface of each sample by use of a Silicon crystal analyzer. A Dectris Pilatus $1 \mathrm{M}$ detector collected 2D scattering patterns, including those shown in Fig. 5. Each scattering pattern was tiled together from three 1 second images with the detector slightly moved between exposures, such that the resulting image removes gaps between the detector modules. The sample to detector distance was measured using a silver behenate scattering standard. Data was analysed using a modified version of the NIKA small angle scattering analysis package. ${ }^{36}$

\section{Device preparation and characterization}

Organic thin film transistors substrates in bottom gate/bottom contact configuration were bought from Fraunhofer IPMS (OFET Gen. 4). Heavily n-doped silicon (doping at wafer surface: $n \sim 3 \times 10^{17} \mathrm{~cm}^{-3}$ ) was used as substrate and gate electrode. Thermally grown silicon oxide $(230 \mathrm{~nm} \pm 10 \mathrm{~nm})$ was used as the gate dielectric. Gold electrodes ( $30 \mathrm{~nm}$ on $10 \mathrm{~nm}$ ITO as adhesion layer) were used as source and drain contacts. The channel width was $10 \mathrm{~mm}$ for all devices and channel lengths of $10 \mu \mathrm{m}$ and $20 \mu \mathrm{m}$ were used. The substrates were cleaned subsequently in acetone and 2-propanol in an ultrasonic bath for 10 minutes each. Treatment in an ozone oven at $50{ }^{\circ} \mathrm{C}$ for 20 min was followed by immersion in a $1 \mathrm{wt} \%$ solution of octyltrichlorosilane in toluene at $60{ }^{\circ} \mathrm{C}$ for $60 \mathrm{~min}$. After rinsing with toluene and 2-propanol the substrates were dried in a nitrogen stream and the polymer was spincoated from a $6 \mathrm{mg} \mathrm{mL}^{-1}$ chloroform solution at $2000 \mathrm{rpm}$ under ambient conditions. Devices were measured in a nitrogen atmosphere using an Agilent B1500 Semiconductor Parameter Analyzer. The devices were annealed in a nitrogen atmosphere at a maximum of $0.9 \mathrm{ppm} \mathrm{O}_{2}$ for 15 minutes consecutively at the temperatures given in the main text. Mobilities were calculated from the slopes in the $\left(I_{\mathrm{d}}\right)^{0.5}-V_{\mathrm{g}}$ plots in the saturation regime using eqn (3) where $I_{\mathrm{d}}$ is the drain current, 
$W$ the channel width, $L$ the channel length, $C_{\mathrm{i}}$ the capacitance, $V_{\mathrm{g}}$ the gate voltage and $V_{\mathrm{T}}$ the threshold voltage, respectively.

$$
I_{\mathrm{d}} \approx \frac{W}{2 L} C_{\mathrm{i}} \mu\left(V_{\mathrm{g}}-V_{\mathrm{T}}\right)^{2}
$$

\section{Synthesis procedures for the DPP compounds}

All syntheses were conducted under argon using a double manifold Schlenk line. Glasware was severely dried under high vacuum. Solvents were degassed by three freeze-pump-thaw cycles. Monomers used for polymerization were recrystallized freshly on the same day.

PDPP $[\mathbf{T}]_{2}$-TPT. An oven dried microwave vial was loaded with DPP $[\mathrm{T}]_{2}\{2 \mathrm{DTd}\}_{2} \mathrm{Br}_{2}$ (124.4 mg, $\left.0.110 \mathrm{mmol}\right)$, 1,4-bis(5(trimethylstannyl)thiophen-2-yl)benzene (62.85 mg, $0.111 \mathrm{mmol}$ ), tri-o-tolylphosphine $(3.92 \mathrm{mg}, 13 \mu \mathrm{mol})$ and finally tris(dibenzylideneacetone)dipalladium(0) (3.15 mg, $3.4 \mu \mathrm{mol})$. Dry and degassed chlorobenzene $(3.0 \mathrm{~mL})$ was added, the vial was sealed with a septum cap and subsequently purged with argon for $15 \mathrm{~min}$. The mixture was stirred for $30 \mathrm{~min}$ at $180{ }^{\circ} \mathrm{C}$ in the microwave. After cooling to $50{ }^{\circ} \mathrm{C} 2$-tributyltinthiophene (25 $\mu \mathrm{L}, 79 \mu \mathrm{mol}$ ) was added to the green gel using a microliter syringe. The mixture was again heated at $180{ }^{\circ} \mathrm{C}$ for $5 \mathrm{~min}$ in the microwave, cooled to $50{ }^{\circ} \mathrm{C}$ and finally 2-bromothiophene (30 $\mu \mathrm{L}, 308 \mu \mathrm{mol}$ ) was added. The mixture was heated to $180{ }^{\circ} \mathrm{C}$ for $5 \mathrm{~min}$ in the microwave. After cooling to room temperature the polymer was precipitated in $200 \mathrm{~mL}$ methanol and filtrated into a Soxhlet thimble. The crude polymer was subjected to Soxhlet extraction using acetone, hexane, dichloromethane and chloroform. The chloroform fraction was concentrated to $4 \mathrm{~mL}$ under reduced pressure and precipitated in $200 \mathrm{~mL}$ methanol. Filtration over a $0.45 \mu \mathrm{m}$ PTFE filter followed by drying in high vacuum afforded PDPP $[\mathrm{T}]_{2}-\mathrm{TPT}$ as a dark purple solid (91 $\mathrm{mg}$, 68\%). ${ }^{1} \mathrm{H}$ NMR (300 MHz, TCE): $\delta$ (ppm) 5.85 (br, s), 7.69-7.37 (br, m), 4.10 (br, s, $\mathrm{R}_{2} \mathrm{~N}-\mathrm{CH}_{2}-$ ), 2.08 (br, s, $-\mathrm{R}_{2} \mathrm{CH}-$ ), 1.44-1.34 (br, m, $-\mathrm{CH}_{2}-$ ), $0.95\left(\mathrm{~m},-\mathrm{CH}_{3}\right)$.

$\mathbf{P D P P}[\mathbf{T}]_{2}-\mathbf{T P F}_{2} \mathbf{T}$. An oven dried microwave vial was loaded with $\mathrm{DPP}[\mathrm{T}]_{2}\{2 \mathrm{DTd}\}_{2} \mathrm{Br}_{2}$ (148.80 $\left.\mathrm{mg}, 0.132 \mathrm{mmol}\right),\left(5,5^{\prime}-(2,5-\right.$ difluoro-1,4-phenylene)bis(thiophene-5,2-diyl))bis(trimethylstannane) (79.33 mg, $0.131 \mathrm{mmol})$, tri-o-tolylphosphine $(5.43 \mathrm{mg}$, $18 \mu \mathrm{mol})$ and finally tris(dibenzylideneacetone)dipalladium(0) (4.23 mg, $4.6 \mu \mathrm{mol})$. Dry and degassed chlorobenzene $(5.0 \mathrm{~mL})$ was added, the vial was sealed with a septum cap and subsequently purged with argon for $15 \mathrm{~min}$. The mixture was stirred for $30 \mathrm{~min}$ at $180{ }^{\circ} \mathrm{C}$ in the microwave. After cooling to $50{ }^{\circ} \mathrm{C}$ 2-tributyltinthiophene $(25 \mu \mathrm{L}, 79 \mu \mathrm{mol})$ was added to the green gel using a microliter syringe. The mixture was again heated at $180{ }^{\circ} \mathrm{C}$ for $5 \mathrm{~min}$ in the microwave, cooled to $50{ }^{\circ} \mathrm{C}$ and finally 2-bromothiophene $(30 \mu \mathrm{L}, 308 \mu \mathrm{mol})$ was added. The mixture was heated to $180{ }^{\circ} \mathrm{C}$ for $5 \mathrm{~min}$ in the microwave. After cooling to room temperature the polymer was precipitated in $200 \mathrm{~mL}$ methanol and filtrated into a Soxhlet thimble. The crude polymer was subjected to Soxhlet extraction using methanol, acetone, hexane, dichloromethane and chloroform. The chloroform fraction was concentrated to $4 \mathrm{~mL}$ under reduced pressure and precipitated in $200 \mathrm{~mL}$ methanol. Filtration over a $0.45 \mu \mathrm{m}$
PTFE filter followed by drying in high vacuum afforded $\mathrm{PDPP}[\mathrm{T}]_{2}-\mathrm{TPF}_{2} \mathrm{~T}$ as a dark purple solid $(131 \mathrm{mg}, 70 \%) .{ }^{1} \mathrm{H}$ NMR (300 MHz, TCE): $\delta$ (ppm) 8.84 (br, s), 7.40-7.24 (br, m), 4.11 (br, s, $\mathrm{R}_{2} \mathrm{~N}-\mathrm{CH}_{2}-$ ), 2.06 (br, s, $-\mathrm{R}_{2} \mathrm{CH}-$ ), 1.44-1.34 (br, m, $-\mathrm{CH}_{2}-$ ), 0.95 (br, s, $\left.-\mathrm{CH}_{3}\right) ;{ }^{19} \mathrm{~F}$ NMR (282 MHz, TCE) $\delta$ (ppm) -117.96.

$\mathbf{P D P P}[\mathbf{T}]_{2}-\mathbf{T P F}_{\mathbf{4}} \mathbf{T}$. An oven dried microwave vial was loaded with DPP $[\mathrm{T}]_{2}\{2 \mathrm{DTd}\}_{2} \mathrm{Br}_{2}$ (163.46 mg, $0.144 \mathrm{mmol}$ ), (5,5'-(perfluoro1,4-phenylene)bis(thiophene-5,2-diyl))bis(trimethylstannane) (93.37 mg, $0.144 \mathrm{mmol}$ ), tri-o-tolylphosphine (5.20 mg, $17 \mu \mathrm{mol}$ ) and finally tris(dibenzylideneacetone)dipalladium(0) $(3.92 \mathrm{mg}$, $4.3 \mu \mathrm{mol})$. Dry and degassed chlorobenzene $(5 \mathrm{~mL})$ was added, the vial was sealed with a septum cap and subsequently purged with argon for $15 \mathrm{~min}$. The mixture was stirred for $30 \mathrm{~min}$ at $180{ }^{\circ} \mathrm{C}$ in the microwave. After cooling to $50{ }^{\circ} \mathrm{C}$ 2-tributyltinthiophene (25 $\mu \mathrm{L}, 79 \mu \mathrm{mol}$ ) was added to the green gel using a microliter syringe. The mixture was again heated at $180{ }^{\circ} \mathrm{C}$ for $5 \mathrm{~min}$ in the microwave, cooled to $50{ }^{\circ} \mathrm{C}$ and finally 2-bromothiophene $(30 \mu \mathrm{L}$, $308 \mu \mathrm{mol}$ ) was added. The mixture was heated to $180{ }^{\circ} \mathrm{C}$ for $5 \mathrm{~min}$ in the microwave. After cooling to room temperature the polymer was precipitated in $250 \mathrm{~mL}$ methanol and filtrated over a $0.45 \mu \mathrm{m}$ PTFE filter. The crude polymer was subjected to Soxhlet extraction using methanol, acetone, hexane and dichloromethane. The solid remains were refluxed in $150 \mathrm{~mL}$ chloroform for $2 \mathrm{~h}$ and filtrated. The filtrate was then concentrated to $4 \mathrm{~mL}$ under reduced pressure and precipitated in $200 \mathrm{~mL}$ methanol. Filtration over a $0.45 \mu \mathrm{m}$ PTFE filter followed by drying in high vacuum afforded PDPP $[\mathrm{T}]_{2}-$ $\mathrm{TPF}_{4} \mathrm{~T}$ as a dark purple solid (108 mg, 52\%). ${ }^{1} \mathrm{H}$ NMR (300 MHz, TCE): $\delta$ (ppm) 8.85 (br, s), 7.71-7.15 (br, m), 4.10 (br, s, $\mathrm{R}_{2} \mathrm{~N}-\mathrm{CH}_{2}-$ ), 2.07 (br, s, $-\mathrm{R}_{2} \mathrm{CH}$ ), 1.44-1.33 (br, m, $-\mathrm{CH}_{2}^{-}$), 0.95 (br, m, $-\mathrm{CH}_{3}$ ); ${ }^{19}$ F NMR (282 MHz, TCE) $\delta(\mathrm{ppm})-139.97$.

\section{Conclusions}

Diketopyrrolo[3,4-c]pyrrole copolymers incorporating an extended thiophene-phenylene-thiophene moiety with varying degrees of fluorination have been successfully synthesized. The concept of fluorination was evaluated in terms of alignment and solid state packing. As evident from GIWAXS, fluorination has a small influence on the alkyl spacing distance as well as the $\pi-\pi$ stacking distance. However, the crystal coherence length can be significantly improved upon fluorination. Furthermore, we showed that upon gradual increase of fluorination and annealing the edge-on alignment of the polymer chains improves significantly, resulting in almost perfect edge-on alignment throughout the complete bulk of the film in the tetrafluorinated derivative. Whereas alignment is improved, fluorination does not necessarily lead to improved hole transport, but is a good approach to achieve ambipolar character in otherwise p-type materials. From our results we are able to draw concrete structure property relationships and their interplay regarding the degree of fluorination on alignment and charge carrier transport.

\section{Acknowledgements}

We acknowledge financial support from DFG (SFB 840) and the Bavarian State Ministry of Education, Science and the Arts 
(Solar technologies go hybrid). C.J.M. thanks the Fonds der Chemischen Industrie for funding the $\mathrm{PhD}$ with a Kekule scholarship and the German National Academic Foundation for other support during the PhD. Support from the Elitenetzwerk Bayern (ENB), Macromolecular Science is also kindly acknowledged. Work in Australia was supported by the Australian Research Council (grant DP13012616). This research was undertaken in part on the SAXS/WAXS beamline at the Australian Synchrotron, Victoria, Australia. ${ }^{35}$

\section{References}

1 X. Zhang, L. J. Richter, D. M. DeLongchamp, R. J. Kline, M. R. Hammond, I. McCulloch, M. Heeney, R. S. Ashraf, J. N. Smith, T. D. Anthopoulos, B. Schroeder, Y. H. Geerts, D. A. Fischer and M. F. Toney, J. Am. Chem. Soc., 2011, 133, 15073-15084.

2 Z. Yi, S. Wang and Y. Liu, Adv. Mater., 2015, 27, 3589-3606.

3 Z. Chen, M. J. Lee, R. Shahid Ashraf, Y. Gu, S. Albert-Seifried, M. Meedom Nielsen, B. Schroeder, T. D. Anthopoulos, M. Heeney, I. McCulloch and H. Sirringhaus, Adv. Mater., 2012, 24, 647-652.

4 I. Kang, H. J. Yun, D. S. Chung, S. K. Kwon and Y. H. Kim, J. Am. Chem. Soc., 2013, 135, 14896-14899.

5 W. Li, K. H. Hendriks, A. Furlan, W. S. Roelofs, S. C. Meskers, M. M. Wienk and R. A. Janssen, Adv. Mater., 2014, 26, 1565-1570.

6 W. Li, K. H. Hendriks, A. Furlan, W. S. C. Roelofs, M. M. Wienk and R. A. J. Janssen, J. Am. Chem. Soc., 2013, 135, 18942-18948.

7 Z. Yi, L. Ma, B. Chen, D. Chen, X. Chen, J. Qin, X. Zhan, Y. Liu, W. J. Ong and J. Li, Chem. Mater., 2013, 25, 4290-4296.

8 M. J. Cho, J. Shin, T. R. Hong, H. A. Um, T. W. Lee, G. W. Kim, J. H. Kwon and D. H. Choi, Polym. Chem., 2014, 6, 150-159.

9 H. G. Kim, B. Kang, H. Ko, J. Lee, J. Shin and K. Cho, Chem. Mater., 2015, 27, 829-838.

10 J. D. Yuen, J. Fan, J. Seifter, B. Lim, R. Hufschmid, A. J. Heeger and F. Wudl, J. Am. Chem. Soc., 2011, 133, 20799-20807.

11 N. E. Jackson, B. M. Savoie, K. L. Kohlstedt, M. Olvera de la Cruz, G. C. Schatz, L. X. Chen and M. A. Ratner, J. Am. Chem. Soc., 2013, 135, 10475-10483.

12 H. Zhong, C. Z. Li, J. Carpenter, H. Ade and A. K. Jen, J. Am. Chem. Soc., 2015, 137, 7616-7619.

13 J. H. Park, E. H. Jung, J. W. Jung and W. H. Jo, Adv. Mater., 2013, 25, 2583-2588.

14 D. J. Crouch, P. J. Skabara, J. E. Lohr, J. J. W. McDouall, M. Heeney, I. McCulloch, D. Sparrowe, M. Shkunov, S. J. Coles, P. N. Horton and M. B. Hursthouse, Chem. Mater., 2005, 17, 6567-6578.

15 D. J. Crouch, P. J. Skabara, M. Heeney, I. McCulloch, S. J. Coles and M. B. Hursthouse, Chem. Commun., 2005, 1465-1467, DOI: $10.1039 / \mathrm{b} 417642 \mathrm{a}$.
16 P. M. Sonar, J. Chang, Z. Shi, J. Wu and J. Li, J. Mater. Chem. C, 2015, 3, 2080-2085.

17 A. Luzio, D. Fazzi, F. Nübling, R. Matsidik, A. Straub, H. Komber, E. Giussani, S. E. Watkins, M. Barbatti, W. Thiel, E. Gann, L. Thomsen, C. R. McNeill, M. Caironi and M. Sommer, Chem. Mater., 2014, 26, 6233-6240.

18 A. de Bettencourt-Dias and A. Poloukhtine, J. Phys. Chem. B, 2006, 110, 25638-25645.

19 D. A. Guthrie and J. D. Tovar, Org. Lett., 2008, 10, 4323-4326.

20 B. G. Kim, E. J. Jeong, J. W. Chung, S. Seo, B. Koo and J. Kim, Nat. Mater., 2013, 12, 659-664.

21 A. K. Palai, S. P. Mishra, A. Kumar, R. Srivastava, M. N. Kamalasanan and M. Patri, Macromol. Chem. Phys., 2010, 211, 1043-1053.

22 C. B. Nielsen, R. S. Ashraf, B. C. Schroeder, P. D’Angelo, S. E. Watkins, K. Song, T. D. Anthopoulos and I. McCulloch, Chem. Commun., 2012, 48, 5832-5834.

23 C. J. Mueller, C. R. Singh, M. Fried, S. Huettner and M. Thelakkat, Adv. Funct. Mater., 2015, 25, 2725-2736.

24 H. Bronstein, J. M. Frost, A. Hadipour, Y. Kim, C. B. Nielsen, R. S. Ashraf, B. P. Rand, S. Watkins and I. McCulloch, Chem. Mater., 2013, 25, 277-285.

25 K. H. Hendriks, W. Li, M. M. Wienk and R. A. J. Janssen, Adv. Energy Mater., 2013, 3, 674-679.

26 J.-L. Bredas, Mater. Horiz., 2014, 1, 17.

27 C. B. Nielsen, M. Turbiez and I. McCulloch, Adv. Mater., 2012, 25, 1859-1880.

28 L. A. Perez, P. Zalar, L. Ying, K. Schmidt, M. F. Toney, T.-Q. Nguyen, G. C. Bazan and E. J. Kramer, Macromolecules, 2014, 47, 1403-1410.

29 A. Facchetti, M. H. Yoon, C. L. Stern, H. E. Katz and T. J. Marks, Angew. Chem., Int. Ed., 2003, 42, 3900-3903.

30 M. H. Yoon, A. Facchetti, C. E. Stern and T. J. Marks, J. Am. Chem. Soc., 2006, 128, 5792-5801.

31 T. Yamao, Y. Taniguchi, K. Yamamoto, T. Miki, S. Ota, S. Hotta, M. Goto and R. Azumi, Jpn. J. Appl. Phys., 2007, 46, 7478-7482.

32 L. L. Chua, J. Zaumseil, J. F. Chang, E. C. Ou, P. K. Ho, H. Sirringhaus and R. H. Friend, Nature, 2005, 434, 194-199.

33 K. Gräf, M. A. Rahim, S. Das and M. Thelakkat, Dyes Pigm., 2013, 99, 1101-1106.

34 V. Mathot, M. Pyda, T. Pijpers, G. Vanden Poel, E. van de Kerkhof, S. van Herwaarden, F. van Herwaarden and A. Leenaers, Thermochim. Acta, 2011, 522, 36-45.

35 N. M. Kirby, S. T. Mudie, A. M. Hawley, D. J. Cookson, H. D. T. Mertens, N. Cowieson and V. Samardzic-Boban, J. Appl. Crystallogr., 2013, 46, 1670-1680.

36 J. Ilavsky, J. Appl. Crystallogr., 2012, 45, 324-328. 